\title{
Correction to: High expression of HO-1 predicts poor prognosis of ovarian cancer patients and promotes proliferation and aggressiveness of ovarian cancer cells
}

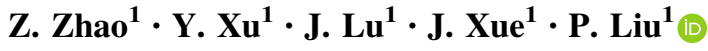

Published online: 20 October 2017

(C) Federación de Sociedades Españolas de Oncología (FESEO) 2017

\section{Correction to: Clin Transl Oncol}

\section{DOI 10.1007/s12094-017-1738-7}

In the original version of the article, Table 2 was incorrect. The corrected Table 2 is shown here. Therefore, in Results (page 3 of original version, right column, line 13), the OR of non-optimal debulking should read $\mathrm{OR}=3.036$ with 95\% CI 1.452-6.348.

The online version of the original article can be found under doi:10.1007/s12094-017-1738-7.

$\triangle$ P. Liu

peishuliu@126.com

1 Department of Obstetrics and Gynecology, Qilu Hospital of Shandong University, 107 Wenhua Xi Road,

Jinan 250012, Shandong, People's Republic of China 
Table 2 Relationships between the expression of $\mathrm{HO}-1$ protein and clinicopathological

characteristics of patients with ovarian cancer

\begin{tabular}{|c|c|c|c|c|c|}
\hline \multirow[t]{2}{*}{ Characteristics } & \multirow{2}{*}{$\begin{array}{l}\text { No. } \\
\text { Cases }\end{array}$} & \multicolumn{2}{|c|}{ HO-1 expression } & \multirow[t]{2}{*}{$P$ value } & \multirow[t]{2}{*}{ OR $(95 \% \mathrm{CI})$} \\
\hline & & Low & High & & \\
\hline Pathologic type & & & & 0.0235 & \\
\hline Serous & 117 & 36 & $81(69.2 \%)$ & 0.6912 & \\
\hline Low-grade serous & 58 & 19 & $39(67.2 \%)$ & & \\
\hline High-grade serous & 59 & 17 & $42(71.2 \%)$ & & \\
\hline Mucinous & 16 & 11 & $5(31.3 \%)$ & & \\
\hline Endometrioid & 25 & 8 & $17(68.0 \%)$ & & \\
\hline Clear cell carcinoma & 21 & 11 & $10(47.6 \%)$ & & \\
\hline Others & 22 & 8 & $14(63.6 \%)$ & & \\
\hline Age & & & & 0.4796 & \\
\hline$\leq 50$ & 113 & 44 & $69(61.1 \%)$ & & \\
\hline$>50$ & 88 & 30 & $58(65.9 \%)$ & & \\
\hline Stage & & & & 0.0017 & $3.656(1.602-8.344)$ \\
\hline I-II & 154 & 66 & $88(57.1 \%)$ & & \\
\hline III-IV & 47 & 8 & $39(83.0 \%)$ & & \\
\hline Differentiation & & & & 0.5572 & \\
\hline G1/G2 & 112 & 39 & $73(65.2 \%)$ & & \\
\hline G3 & 89 & 35 & $54(60.7 \%)$ & & \\
\hline Lymph node metastasis ${ }^{\mathrm{a}}$ & & & & 0.0001 & $7.779(2.280-26.540)$ \\
\hline No & 156 & 67 & $89(57.1 \%)$ & & \\
\hline Yes & 34 & 3 & $31(91.2 \%)$ & & \\
\hline Optimal debulking & & & & 0.0029 & $3.036(1.452-6.348)$ \\
\hline Optimal & 146 & 63 & $83(56.8 \%)$ & & \\
\hline Non-optimal & 55 & 11 & $44(80.0 \%)$ & & \\
\hline
\end{tabular}

${ }^{a}$ Eleven patients without lymph node resection 